\title{
Ready, set, go!: exploring use of a readiness process to implement pharmacy services
}

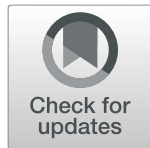

Melanie Livet ${ }^{1^{*}} \mathbb{D}$, Mary Yannayon ${ }^{1}$, Chloe Richard', Lindsay Sorge ${ }^{2,3}$ and Paul Scanlon ${ }^{2,4}$

\begin{abstract}
Background: Readiness is an essential precursor of successful implementation; however, its conceptualization and application has proved elusive. $R=M C^{2}$ operationalizes readiness for use in practice. The purpose of this study was to (1) describe the application of $R=M C^{2}$ to assess and build readiness in nine healthcare sites responsible for implementing medication management services and (2) gain insights into the sites' experience.

Methods: This mixed methods exploratory study used data collected as part of a process evaluation. Understanding application of the readiness process (Aim 1) involved examining team members' involvement (who?), readiness challenges and readiness building strategies (what?), strategy execution (how much?), and resulting changes (for what purpose?). To understand the sites' experience with the $R=M C^{2}$ system (Aim 2), interviews were conducted with six of the sites to identify facilitators, barriers, and lessons learned. Data sources included a document review (e.g., sites' action plans), survey results, and interview data.

Results: Sites included primary care and specialty clinics, pharmacies within health systems, and community pharmacies. Teams consisted of 4-11 members, including a lead pharmacist. The teams' readiness activities clustered into five broad categories of readiness building strategies (e.g., building the operational infrastructure for service integration). Of the 34 strategies identified across sites, $68 \%$ were still in progress after 4 months. Engaging in the readiness process resulted in a number of outputs (e.g., data management systems) and benefits (e.g., an opportunity to ensure alignment of priorities and fit of the intervention). Based on the interviews, facilitators of the readiness process included assistance from a coach, internal support, and access to the readiness tools. Competing priorities and lack of resources, timely decision-making, and the timing of the readiness process were cited as barriers. The importance of service fit, stakeholder engagement, access to a structured approach, and rightsizing the readiness process emerged as lessons learned.
\end{abstract}

Conclusions: These findings provide valuable insights into the application of a readiness process. If readiness is to be integrated into routine practice as part of any implementation effort, it is critical to gain a better understanding of its application and value.

Keywords: Implementation readiness, Readiness building strategies, Readiness facilitators, Readiness barriers, Use of a readiness process, Pharmacy, Medication management services

*Correspondence: melanie.livet@unc.edu

${ }^{1}$ Center for Medication Optimization (CMO), Division of Practice

Advancement and Clinical Education, Eshelman School of Pharmacy,

University of North Carolina at Chapel Hill, Chapel Hill, NC, USA

Full list of author information is available at the end of the article

\section{Introduction}

Implementation readiness has been recognized as an essential precursor of successful implementation [1-6]. A practice setting needs to both be willing and able to carry out a change $[1,6-8]$, whether this change is implementation of a new service, intervention, technology, or policy. Assessing and building readiness has

(c) The Author(s). 2020 Open Access This article is licensed under a Creative Commons Attribution 4.0 International License, which permits use, sharing, adaptation, distribution and reproduction in any medium or format, as long as you give appropriate credit to the original author(s) and the source, provide a link to the Creative Commons licence, and indicate if changes were made. The images or other third party material in this article are included in the article's Creative Commons licence, unless indicated otherwise in a credit line to the material. If material is not included in the article's Creative Commons licence and your intended use is not permitted by statutory regulation or exceeds the permitted use, you will need to obtain permission directly from the copyright holder. To view a copy of this licence, visit http://creativecommons.org/licenses/by/4.0/. The Creative Commons Public Domain Dedication waiver (http://creativecommons.org/publicdomain/zero/1.0/) applies to the data made available in this article, unless otherwise stated in a credit line to the data. 


\section{Contributions to the literature}

- Although implementation readiness (i.e., motivation and capacity) is an essential precursor of successful implementation, its conceptualization has proved elusive. $R$ $=M C^{2}$ operationalizes readiness for use in practice, yet its use and value remain unexplored.

- This is the first published study to systematically explore application of the $R=M C^{2}$ process, with the purpose being to better understand its use in real-world settings.

- This study addresses a recognized gap in the implementation science literature, contributing valuable insights into use of a readiness process. These findings add to the current body of literature by identifying lessons learned that should be considered when building implementation readiness.

oftentimes been overlooked by well-meaning stakeholders eager to jump into action. Discounting readiness can be costly, resulting in avoidable implementation misadventures and, subsequently, failure to achieve the intended outcomes [6, 9]. In fact, failure to establish sufficient readiness prior to implementation accounts for half of all unsuccessful, large-scale organizational change efforts [10]. Readiness should be part of any translational efforts and has been identified as a critical step in implementation practice roadmaps [11] and frameworks [2, 12-14].

Despite the general consensus that readiness is an important aspect of implementation, its conceptualization and application in real-world settings has proved rather elusive $[2,5-7,12,15,16]$. Although organizational change models and theories abound [17-19], very few frameworks operationalize the readiness process for use in practice [20]. One of these frameworks is $\mathrm{R}=M C^{2}$ [20]. Briefly, $R=M C^{2}$ defines readiness as a multifaceted construct that refers to an organization's commitment and collective capability for implementation. It posits that readiness results from the interplay between three components: motivation (i.e., incentives and disincentives that contribute to the desirability of an innovation), general capacity (i.e., conditions related to how well an organization is functioning), and innovation-specific capacity (i.e., conditions needed to implement a specific innovation). The more willing and able an organization is to devote the resources necessary, the greater the likelihood of quality implementation [2, $4-6,21]$. Each of these components is further conceptualized into multiple subcomponents (see Table 1). This heuristic was translated into an assessment and readiness building system that includes practical tools and specific strategies to facilitate execution. The $\mathrm{R}=M C^{2}$ system was used as the readiness framework for this study.

In addition to the sparsity of pragmatic readiness frameworks, the published literature on how to apply these frameworks is in its infancy. To date, there are only two published examples illustrating the application of the $\mathrm{R}=M C^{2}$. The first study uses the $\mathrm{R}=M C^{2}$ readiness monitoring tool (RMT) to monitor changes in five schools' readiness to implement a school safety intervention [22]. In the second article, the authors conducted a Delphi study with community coalition leaders to assess the relative significance of each of the $\mathrm{R}=M \mathrm{C}^{2}$ concepts at different stages of the implementation process [23]. The current study adds to the literature by exploring application of $\mathrm{R}=\mathrm{MC}^{2}$ in healthcare settings. More specifically, $\mathrm{R}=\mathrm{MC}^{2}$ was used to assess and build readiness for implementing medication optimization services as part of a broader pharmacy practice initiative, the Concordia Medication Management Accelerator (CMMA). Briefly, CMMA aimed to accelerate integration of clinical pharmacy services in participating healthcare settings through a structured planning approach that included a readiness phase.

The aims of this mixed methods exploratory study were to (1) describe the application of the process to assess and build readiness in an initial cohort of nine healthcare sites, including seven health systems/clinics (with embedded pharmacists) and two community pharmacies, and (2) understand the experience of participating sites with the readiness process. If readiness is to be integrated into routine practice as part of any implementation effort, it is critical to gain insights into its application and value.

\section{Methods \\ Overview of study design}

This mixed methods exploratory study made use of data collected as part of a process evaluation to better understand the use of the readiness process, as well as the sites' experience with it. The description of the $\mathrm{R}=\mathrm{MC}^{2}$ system as applied to practice (Aim 1) involves understanding the participating teams and their involvement (who?), examining the types of readiness challenges and readiness building strategies used by the sites (what?), summarizing progress on strategy execution (how much?), and investigating resulting changes (for what purpose?). Aim 1 was informed by multiple data sources, including project documents, surveys, and relevant information from site interviews. To understand the sites' experience with the $\mathrm{R}=M C^{2}$ system (Aim 2), interviews were conducted with six of the sites to identify facilitators, barriers, and lessons learned. Following IRB approval, Aim 1 data were collected throughout the 9- 


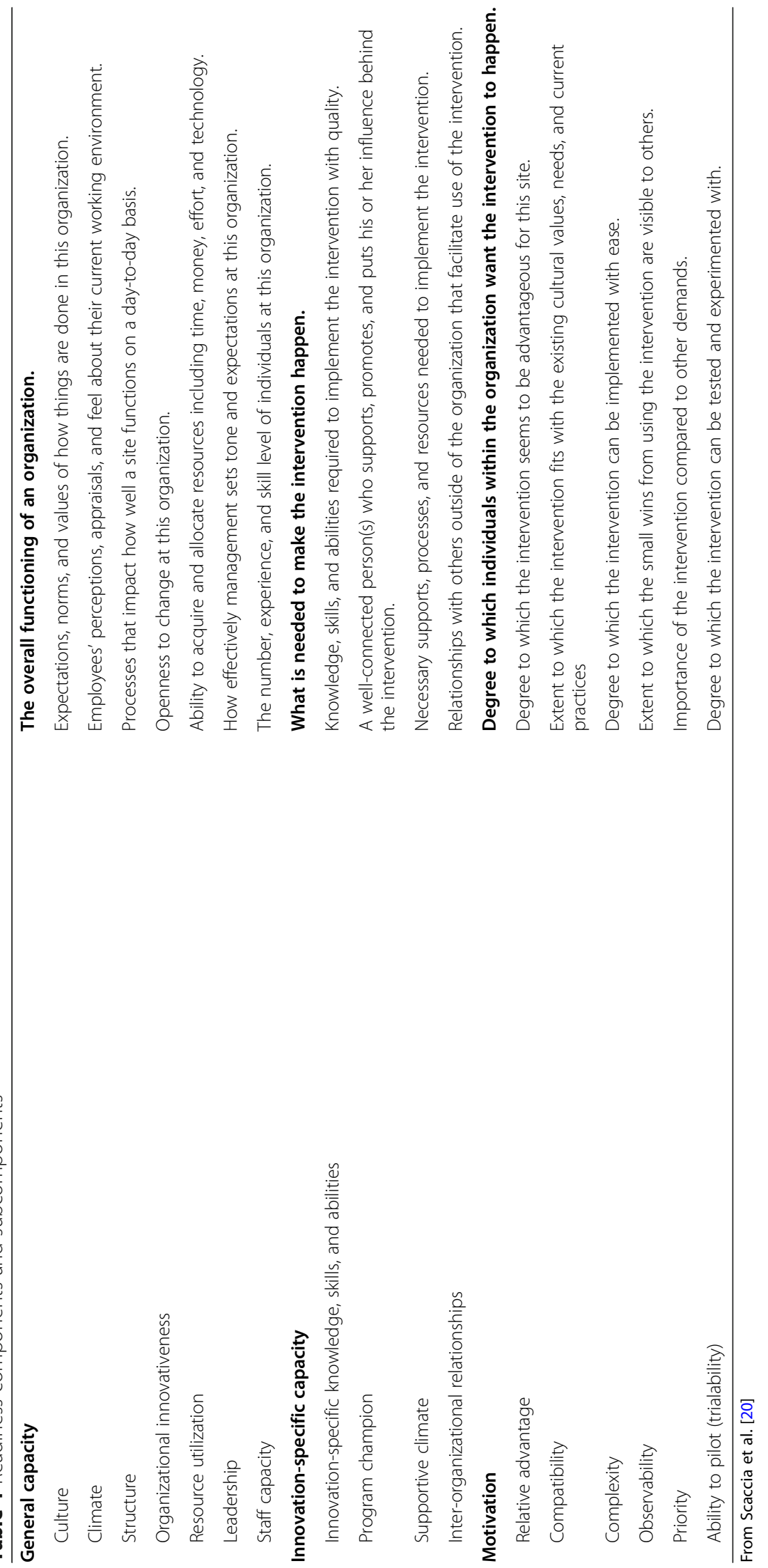


month readiness phase. Aim 2 interviews occurred at the end of the readiness phase.

\section{Readiness in pharmacy practice: the CMMA initiative}

The importance of attending to the implementation process has recently been embraced by pharmacy practice as a potential solution to accelerate the pace of healthcare change, drive effectiveness of medication optimization interventions, and facilitate replication and scaling $[24,25]$. Suboptimal use of medication not only impacts quality of care, but it is also one of the most preventable problems contributing to rising healthcare costs (e.g., $\$ 528$ billion annually spent on addressing medication misuse vs $\$ 450$ billion spent on prescriptions) $[26,27]$. Interest in the process of implementation has been fueled by both the transition to value-based care and the lack of conclusive effectiveness outcomes in the medication optimization literature [25, 28, 29]. Reducing implementation variability through planned and systematic delivery of services begins with assessing and building readiness.

The Concordia Medication Management Accelerator (CMMA) was an 18-month initiative to integrate medication optimization services into primary care settings across the health system in Wisconsin. This initiative was sponsored by the Concordia University Wisconsin's School of Pharmacy in partnership with the Batterman School of Business. Funding for this initiative was a personal gift from Erv Dohmen. The nine participating sites, composed of seven health systems/clinics (with embedded pharmacists) and two community pharmacies, were recruited through an open invitation to participate in a live summer event at Concordia University Wisconsin. Any healthcare organization, primary care clinic, health system, and pharmacy across Wisconsin working to advance or adopt medication optimization services within their organization was eligible to participate. Over the course of this project, the sites engaged in a structured planning and implementation process that included readiness as one of its steps. Implementation support, including monthly coaching, webinars, and inperson meetings, were provided to the sites by an external non-profit organization, the Alliance for Integrated Medication Management (AIMM). AIMM works to drive changes in care delivery systems [30]. The readiness project team, composed of two AIMM coaches and the UNC Eshelman School of Pharmacy Center for Medication Optimization (CMO) research group, was specifically dedicated to assessing and building readiness over a 9-month period.

\section{Operationalizing $R=M C^{2}$ in the CMMA initiative}

The $\mathrm{R}=M C^{2}$ process was operationalized into four phases: preparing for readiness (1 month); readiness assessment (3 months); priority identification, goal setting, and action planning (1 month); and strategy execution (4 months).

\section{Preparing for readiness}

Prior to engaging in the readiness work, each participating site was asked to identify a lead pharmacist whose first responsibility was to assemble an implementation team. These teams were responsible for planning and implementing the selected service(s), starting with assessing and building readiness. Once the teams were formed, the concept of readiness, and more specifically $\mathrm{R}=\mathrm{MC}^{2}$, was introduced during two webinars. These webinars were recorded for team members who were unable to attend. In addition, coaches had preliminary discussions with each of the teams to clarify the purpose of the readiness process, explain how this process was integrated into the broader initiative, and address any concerns that were raised by the teams.

\section{Assessing readiness}

During the readiness assessment phase, each team completed the RMT. To assist the teams with use of the RMT data, the CMO research group created individual heatmap reports. These reports provided reminder information about readiness, RMT assessment results specific to the team, a list of strengths, challenges, and key insights, and a summary designed to assist with selection of priority readiness building areas. The heatmap reports were shared with teams via email and discussed during their regularly scheduled coaching check-ins. These collaborative discussions were not only necessary for the teams to understand their results, but proved to be critical to help guide priority setting.

\section{Identifying priorities, setting goals, and action planning}

Following these discussions, the teams prioritized their readiness challenges on feasibility and impact (high or low) using a four-quadrant priority matrix. These priorities were then translated into actionable readiness goals with assistance from the coaches. Simultaneously, the $\mathrm{CMO}$ research group assembled a preliminary list of relevant readiness building strategies for each team based on the RMT results and priorities. At least one strategy was identified for each RMT item that was recognized as a priority issue for readiness building. The recommended strategies were shared with the coaches and teams to facilitate concrete discussions for action planning. Ultimately, the teams decided on the most relevant strategies for their action plan.

\section{Readiness building strategies execution}

Teams were asked to execute on their selected readiness building strategies over a 4-month period. During this 
period, coaches checked in monthly and used the action plan to monitor progress and facilitate discussions around challenges and potential solutions.

\section{Data collection procedures and data sources}

Aim 1 data sources consisted of the following: project documents (i.e., the sites' readiness action plans, coaching logs, and the readiness project team notes); two surveys, including a demographics survey that was distributed to each team member at each site, and the RMT that was completed by each team as part of the readiness process; and Aim 2 interview information specifically related tochanges made as a result of engaging in the readiness process. Aim 2 data were generated through interviews with six lead pharmacists, one from each site. Although the invitation to interview was extended to all the participating sites, two of the lead pharmacists were unable to participate due to time constraints. Participant consent was obtained prior to both surveys and interviews. Figure 1 provides an overview of data sources, analysis, and resulting data outputs.

\section{Surveys}

The demographics survey was completed by team members at the end of the project. In addition to demographic questions (e.g., gender, age, ethnicity, race, highest degree completed, professional role), the survey for the lead pharmacist included items inquiring about the level of involvement of each team member in the readiness process (i.e., completing the readiness assessment, reviewing the report and identifying priorities, developing the action plan, executing on the readiness building strategies, and reviewing progress of readiness actions). Ratings ranged from "not at all involved" to "fully involved" on a 3-point scale.

The RMT used in this study was a 67-item Likert-scale created to assess level of readiness for implementation. It is composed of three scales, aligned with the three components that conceptually define readiness (i.e., motivation, general capacity, innovation-specific capacity). Each of the scales is further divided into subscales representing the 17 subcomponents (e.g., culture, program champion) (see Table 1). Items (e.g., the team has the concrete skills needed to implement the selected service) are scored on a 7-point Likert scale, ranging from

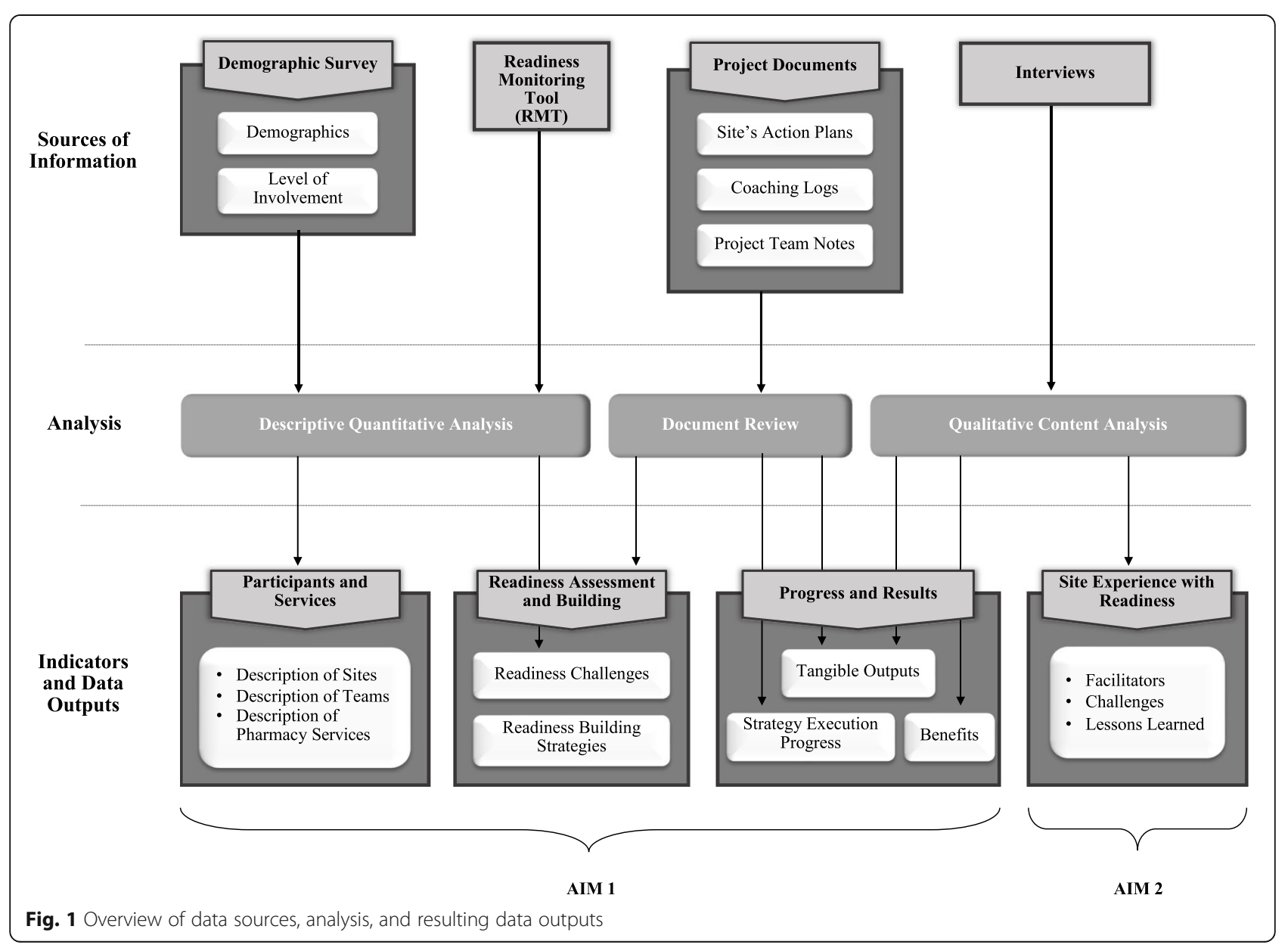


strongly disagree to strongly agree with a neutral option. Minor wording changes were made to the original RMT [31] to reflect the study context (e.g., "organization" to "site"). The original RMT is available from its developers at the Wandersman Center. This measure was shown to have good reliability (Cronbach's alpha; $\alpha \geq 0.070$ for $89 \%$ of the subcomponent index scores) [31]. In addition to rating the RMT Likert-type items, the team was also asked to generate their top three readiness insights.

\section{Project documents}

The data sources for the document review included the sites' readiness action plans, the coaching logs, and the readiness project team notes. Action plans were completed by each site as part of the readiness process. In these plans, the sites documented their readiness priorities/goals, their readiness building strategies, associated tasks, the team member(s) responsible for completing these tasks, due dates, and progress to date. The coaching logs were completed by the coaches after each site's check-in to document readiness-related discussions. Although the coaching logs included additional information (e.g., date of contact, coaching recipient, coach name, duration of the coaching session), the discussion notes were the only data used in the current study. Finally, the project team notes included both summaries of conversations among the readiness project team members (research team and coaches) $(N=9)$ and the notes taken by the research team members when able to attend the coaching calls $(N=16)$.

\section{Interviews}

An interview protocol was created to standardize the semi-structured interviews. The interview questions, which were provided to the participants ahead of time, were designed to identify what worked well with the readiness process, the challenges that were encountered, the changes that were experienced as a result of the readiness building process, and lessons learned. While these questions helped define the areas to be explored, the interviewer and interviewee were allowed to diverge to pursue an idea in more detail [32]. To ensure that they had a common frame of reference when responding to these questions, participants were reminded of the specific activities that were part of the readiness process (e.g., completing the readiness assessment, identifying priorities). They were also provided with a summary of these activities for their specific team (e.g., one of your priority readiness goals was to obtain buy-in for comprehensive medication management (CMM) from your office manager). These 30-min interviews were conducted over a 2-week period by a trained interviewer. They were transcribed verbatim to facilitate analysis following consent from each participant.

\section{Data analysis \\ Surveys}

Descriptive statistics (frequencies, means) were calculated across respondents on the demographics survey to obtain a description of the participants across teams. In addition, the level of involvement items in the demographics survey were averaged across readiness activities and participants for each team, resulting in percent involvement. Finally, RMT survey scores were created by averaging survey items across teams. Means, standard deviations, and frequencies were computed by components and subcomponents. Components and subcomponents with a mean rating equal or above 4.5 represented high levels of readiness, between 3.5 and 4.49 as moderate, and below 3.5 as low.

\section{Document review}

The document review was used as a methodology to provide data on application of the readiness system [33]. As for other types of qualitative analyses, document analysis involves review of the information from the different data sources, abstraction into categories of interest, and interpretation to elicit meaning and understanding. Information from all data sources (coaching logs, action plans, and notes) was first compiled for each site separately in a $\log$ that ordered these data chronologically. These site logs were then reviewed and abstracted into site-specific spreadsheets by two members of the CMO research team using the following categories: priority/ goal, RMT components/subcomponents, readiness building strategies, and progress to date. The CMO research team then reviewed, interpreted, and standardized this information through discussion and consensus building [34]. These data were aggregated across sites to summarize the sites' priorities, readiness building strategies, and progress.

\section{Interviews}

Interview transcripts were analyzed using content analysis [35]. During the pre-coding stage, the analyst read the transcripts to become familiar with the material. Primary codes were then applied to each relevant line of text, with secondary codes emerging as a result of a second read. Primary codes included successes/facilitators, challenges, changes, and lessons learned. The codebook was refined to include primary and secondary codes. The third read involved focused coding of the transcripts. The information was synthesized into a spreadsheet that included the codes, subcodes, and relevant transcript text for each site, allowing for comparisons across sites and codes. The analysis was conducted by the second author, with quality assurance checks performed by the third author on $20 \%$ of the 
interviews. Kappa coefficients demonstrate agreement between analysts, with a Cohen's kappa of 0.88 .

\section{Results}

Understanding use of the readiness process (Aim 1)

Sites, teams, and pharmacy services

All but one site (that dropped out of the broader initiative due to changes in priorities) engaged in the readiness assessment and building activities. This convenience sample included six health systems/clinics and two community pharmacies. Figure 2 provides a brief description of each site. Sites included primary care and specialty clinics within health systems, outpatient pharmacies within health systems, and community pharmacies. The medication optimization services and projects that were selected for implementation were unique to the needs of each site. Examples included comprehensive medication management (CMM), medication therapy management (MTM), medication synchronization (Med Sync), multi-faceted medication adherence programs (e.g., comprehensive medication reviews (CMRs), bubble packing), and diabetes management. In addition, because each site differed in the intended scope of implementation (e.g., one vs. multiple settings), the levels at which readiness needed to be built was also varied. While some sites focused on readiness building in one setting, others selected to build readiness in multiple settings and/or at the health system level (Fig. 2).

Each implementation team included between 4 and 11 members, including at least one pharmacist, medical professionals (e.g., nurse practitioner, physician), administrators and support staff (e.g., operations manager), patient advocates and educators, behavioral health (e.g., psychologist), and other relevant stakeholders (e.g., dietitian) (Table 2). When examining the level of involvement of each team member (reported on the demographics survey), it is worth noting that $1-3$ individuals per team (rather than the full team) were fully engaged with completion of all of the readiness assessment and building activities (Table 2). A brief description of each team's intervention focus is also included in Table 2.

\section{Readiness challenges and readiness building strategies}

Baseline RMT scores for all of the sites were high across readiness components and subcomponents, with means above 4.5 (Table 3). Based on an itemlevel analysis average across the sites, there seems to

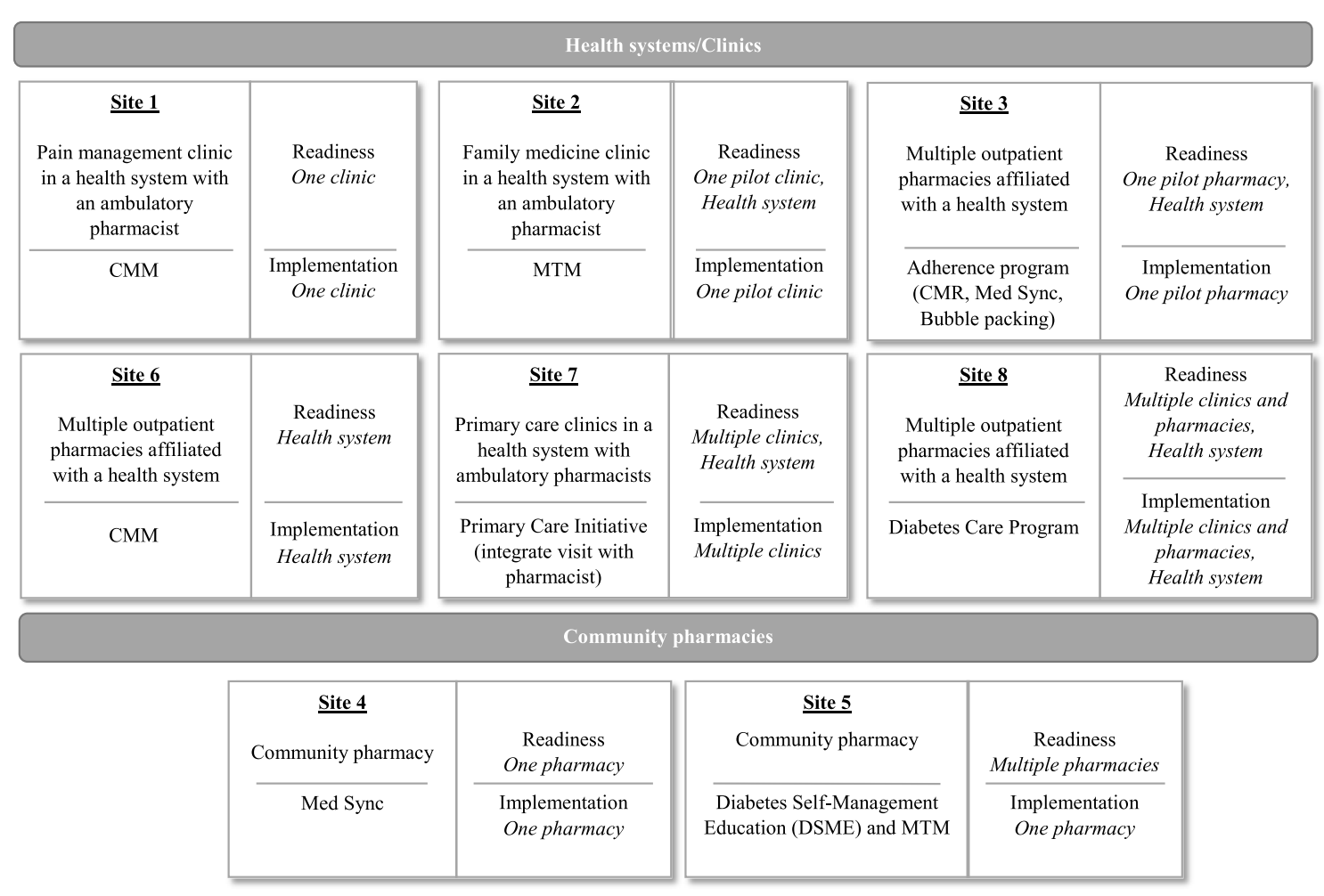

Readiness refers to the level or target of readiness activities, Implementation refers to the level or target of implementation activities, CMM Comprehensive Medication Management, MTM Medication Therapy Management, CMR Comprehensive Medication Review, Med Sync Medication Synchronization 
be uncertainty around the ease of implementing the intervention (i.e., the team believes that the selected intervention is easy to implement, $M=3.89$ ) and resource allocation (i.e., there is a clear process by which we prioritize and distribute resources, $M=$ 4.33). Based on the document review, the coaches' discussions with each of the sites about their assessment results uncovered additional readiness challenges. The compiled list of prioritized challenges is presented in Table 4. Operational integration of the service and stakeholder engagement/buy-in were selected as priority challenges by the majority of the

Table 2 Description of intervention focus and teams

\begin{tabular}{l} 
Site Intervention Focus \\
\hline 1 Implement CMM and position pharmacist as a physician extender \\
2 Implement MTM to reduce heart failure admissions and improve diabetes care \\
3 Combine CMRs, bubble packing, and Med Sync into a comprehensive adherence \\
program
\end{tabular}
Implement Med Sync to increase patient adherence

5 Implement CMM to reduce the overall cost for high-risk employee patients Incorporate a follow-up pharmacotherapist visit for patients with chronic conditions

8 Develop a collaborative coordinated diabetes care program to reduce overall cost for high-cost employee patients
Team members

$\mathrm{N}$ Role $(N$ if $>1)$

Involvement $(N)$

9 Clinical Pharmacist* Clinical Pharmacy

Manager

Psychologist

Physicians (2)

Physician's Assistant

Medical Assistants (3)

8 Clinical Pharmacy

Manager*

Clinical Pharmacy

Resident*

Operations Manager

Operations Supervisor

Nurse Practitioner

Physicians (3)

9 Clinical Pharmacy Coordinators(2)*

Clinical Pharmacists (3)

Pharmacy Services

Director

Pharmacy Manager

Pharmacy Resident

Physician

4 Pharmacy Resident* Clinical Pharmacist Patient Care Advocate Patient Care Advocate Assistant

4 Clinical Pharmacist* (2) Pharmacist* Pharmacy Technician

8 Pharmacy Director* (2) Pharmacy Manager (2) Pharmacists (3) Pharmacy Resident

10 Pharmacy Resident* Pharmacy Manager* Pharmacists (3)

Physicians* (3) Data Analyst Marketing

11 Director of Pharmacy* Physician

Clinic Nurse Manager Pharmacist Manager (2) RN Diabetes Educator* Health and Fitness

Coordinator

Dietitian

Program Educator* (2)

Rehab Director
$25 \%$ fully involved (2)

$11 \%$ fully involved (1) $89 \%$ not involved (8) $75 \%$ not involved (6)

$22 \%$ fully involved (2) $78 \%$ not involved (7)

25\% fully involved (1) $75 \%$ not involved (3)

$50 \%$ fully involved (2) $50 \%$ not involved (2)

$13 \%$ fully involved (1) $26 \%$ somewhat involved (2) $61 \%$ not involved (5) $33 \%$ fully involved (3) $70 \%$ not involved (7)

27\% fully involved* (3) $55 \%$ somewhat involved (6) $18 \%$ not involved (2) 
Table 3 Readiness scores by component and subcomponent (across sites)

\begin{tabular}{|c|c|c|c|c|}
\hline \multirow[t]{3}{*}{ Component and subcomponent } & \multicolumn{4}{|l|}{$\underline{\text { Sites }}$} \\
\hline & \multirow{2}{*}{$\begin{array}{l}\text { Mean (SD) } \\
(N=8)\end{array}$} & \multicolumn{3}{|l|}{ Frequencies $(N)$} \\
\hline & & High scores, $\geq 4.5$ & Neutral scores, 3.5 to 4.49 & Low scores, $<3.5$ \\
\hline General capacity & $5.75(0.61)$ & 8 & & \\
\hline Culture & $6.06(0.65)$ & 8 & & \\
\hline Climate & $5.81(0.76)$ & 8 & & \\
\hline Structure & $5.78(0.82)$ & 7 & 1 & \\
\hline Organizational innovativeness & $5.85(1.02)$ & 7 & 1 & \\
\hline Resource utilization & $4.91(0.84)$ & 6 & 2 & \\
\hline Leadership & $6.02(0.6)$ & 8 & & \\
\hline Staff capacity & $5.79(0.99)$ & 7 & 1 & \\
\hline Innovation-specific capacity & $5.53(1.03)$ & 7 & & 1 \\
\hline Innovation-specific knowledge, skills, and abilities & $5.92(0.81)$ & 7 & 1 & \\
\hline Program champion & $6.04(1.03)$ & 7 & 1 & \\
\hline Implementation supports & $5.18(0.95)$ & 5 & 3 & \\
\hline Inter-organizational relationships & $4.88(1.92)$ & 6 & & 2 \\
\hline Motivation & $5.72(0.34)$ & 8 & & \\
\hline Relative advantage & $5.46(1.01)$ & 6 & 2 & \\
\hline Compatibility & $6.34(0.5)$ & 8 & & \\
\hline Complexity & $6.71(1.05)$ & 6 & 1 & 1 \\
\hline Observability & $5.46(0.45)$ & 8 & & \\
\hline Priority & $5.46(1.07)$ & 6 & 2 & \\
\hline Ability to pilot & $5.5(0.96)$ & 7 & 1 & \\
\hline
\end{tabular}

Means denote the level of readiness from 1 (lowest) to 7 (highest)

sites (all but one site, and five of the eight sites, respectively). The readiness building strategies used by the sites were aligned with their priority challenges. Table 4 provides a list of strategies used by the sites, as well as specific examples.

\section{Progress on strategy execution and resulting changes}

Of the 34 readiness building strategies identified across sites, $23 \%$ of strategies $(N=8)$ had been completed, $68 \%$ $(N=23)$ were in progress, and $9 \%(N=3)$ had not been addressed (Table 5). Three of the eight sites reported completing strategies, while all the sites reported some progress towards execution of the strategies.

Changes resulting from engaging in the readiness process fell into two categories: tangible outputs and benefits. Tangible outputs included data management systems; billing pathways, payment methodologies, and reimbursement models for the service; trainings and educational materials; service workflows; staffing plans; referral processes; and patient data repositories. Benefits included increased awareness of readiness challenges; an opportunity to ensure alignment of service priorities across the clinic/health system (e.g., "What the readiness results really showed me is that I need to make sure that this is a priority not just for me, but also for the health system and the providers I work with"); the ability to clarify the service that was most appropriate for existing needs (e.g., "in talking with those stakeholders, it really kind of changed my mind a whole lot. I started looking more at okay, is this more Comprehensive Medication Management that I'm doing, is it more just pain specific medication management that I'm doing, and so I took a step back and looked at the big picture for my health system and then providers"); an opportunity to build a case for the service to facilitate communication, increase buy-in, and promote engagement and action (e.g., "We did put out some targeted communication to our pharmacist team to help demonstrate what we were doing and why we were doing it, and to get further people engaged in participating in the process"); and the ability to organize readiness tasks and track progress, with one site mentioning continuing to use this process in other implementation initiatives. 
Table 4 Prioritized readiness challenges and readiness building strategies

\begin{tabular}{|c|c|c|c|c|}
\hline $\begin{array}{l}\text { Prioritized } \\
\text { readiness } \\
\text { challenges }\end{array}$ & $\begin{array}{l}\text { Readiness building } \\
\text { strategies }\end{array}$ & Site examples & Sites & Stage \\
\hline \multirow{10}{*}{$\begin{array}{l}\text { Operational } \\
\text { integration } \\
\text { - Data process and } \\
\text { systems } \\
\text { - Financial } \\
\text { resources } \\
\text { - Patient } \\
\text { information } \\
\text { repository } \\
\text { - Referral process } \\
\text { - Workflow } \\
\text { - Staffing }\end{array}$} & $\begin{array}{l}\text { Build data processes and } \\
\text { systems to track and } \\
\text { monitor }\end{array}$ & $\begin{array}{l}\text { Build data management process and/or system to monitor patient } \\
\text { progress and outcomes (e.g., integration with EPIC) }\end{array}$ & $\begin{array}{l}1,2 \\
5,8\end{array}$ & Implementation \\
\hline & \multirow{3}{*}{$\begin{array}{l}\text { Develop reimbursement/ } \\
\text { financial plan }\end{array}$} & Develop a payment/billing methodology & 6 & Implementation \\
\hline & & $\begin{array}{l}\text { Develop a financial plan to sustain the initiative through meetings with } \\
\text { leadership and by hiring staff }\end{array}$ & 2 & Sustainability \\
\hline & & $\begin{array}{l}\text { Develop and present a scalability plan showcasing pilot data to obtain } \\
\text { additional financial resources through meetings with leadership }\end{array}$ & 3 & Scalability \\
\hline & $\begin{array}{l}\text { Create a patient } \\
\text { information repository }\end{array}$ & $\begin{array}{l}\text { Develop a centralized repository for patient information by partnering with } \\
\text { IT }\end{array}$ & 8 & Implementation \\
\hline & Develop a referral process & $\begin{array}{l}\text { Develop a referral process for service by creating a referral form for } \\
\text { primary care physicians }\end{array}$ & 5 & Implementation \\
\hline & \multirow[t]{2}{*}{$\begin{array}{l}\text { Develop integrated } \\
\text { workflow }\end{array}$} & $\begin{array}{l}\text { Develop workflow for service (e.g., after reviewing current best practices } \\
\text { for service, after completing driver diagram) }\end{array}$ & 2,4 & Implementation \\
\hline & & $\begin{array}{l}\text { Create workflow to meet the capacity needed to reach a larger high-risk } \\
\text { patient population }\end{array}$ & 6 & Scalability \\
\hline & \multirow[t]{2}{*}{$\begin{array}{l}\text { Optimize staffing to } \\
\text { maximize efficiencies }\end{array}$} & $\begin{array}{l}\text { Optimize staffing to maximize efficiencies by transitioning roles and } \\
\text { responsibilities to mitigate staff turnover }\end{array}$ & 4 & Implementation \\
\hline & & $\begin{array}{l}\text { Optimize staffing to maximize efficiencies by modifying roles and } \\
\text { responsibilities to allow pharmacists to focus on billable services }\end{array}$ & 5 & Implementation \\
\hline \multirow{7}{*}{$\begin{array}{l}\text { Stakeholder } \\
\text { engagement and } \\
\text { buy-in }\end{array}$} & \multirow[t]{2}{*}{ Use pilot data } & $\begin{array}{l}\text { Use pilot data for gaining approval from partnering health plan for } \\
\text { payment model }\end{array}$ & 6 & Implementation \\
\hline & & Use of pilot data to increase buy-in from leadership for scaling service & 3 & Scalability \\
\hline & \multirow[t]{3}{*}{$\begin{array}{l}\text { Market/create promotional } \\
\text { messaging }\end{array}$} & $\begin{array}{l}\text { Create and disseminate marketing materials through multiple avenues of } \\
\text { communication (e.g., mailing lists, media outlets) to increase patient and } \\
\text { provider engagement in the service }\end{array}$ & 8 & Implementation \\
\hline & & $\begin{array}{l}\text { Brainstorm promotional messaging for internal marketing materials with } \\
\text { pharmacy managers to increase pharmacist engagement }\end{array}$ & 6 & Implementation \\
\hline & & $\begin{array}{l}\text { Deliver promotional messaging to pharmacists through program } \\
\text { champions (i.e., pharmacists on board) }\end{array}$ & 6 & Implementation \\
\hline & Conduct trainings & $\begin{array}{l}\text { Develop and conduct trainings for pharmacy residents and clinic staff (e.g., } \\
\text { on workflows, data collection) }\end{array}$ & 3,4 & Implementation \\
\hline & Provide education & Educate clinic staff on service and their role & 1 & Implementation \\
\hline \multirow[t]{2}{*}{ Team } & Identify team members & Identify team members responsible for readiness and implementation & 1 & Implementation \\
\hline & Engage team members & $\begin{array}{l}\text { Engage implementation team through online training and showcasing of } \\
\text { positive patient stories to obtain buy-in for the selected service }\end{array}$ & 4 & Implementation \\
\hline \multirow[t]{2}{*}{ Champion } & Identify champion & Identify champion to promote service through discussion with leadership & 1 & Implementation \\
\hline & Leverage champion & $\begin{array}{l}\text { Leverage champion to develop a billing pathway and help prepare for } \\
\text { implementation }\end{array}$ & 1 & Implementation \\
\hline \multirow[t]{3}{*}{ Priority alignment } & $\begin{array}{l}\text { Determine priority for } \\
\text { service }\end{array}$ & $\begin{array}{l}\text { Determine priority for service by reaching out to new leadership once } \\
\text { identified (in midst of merger) }\end{array}$ & 7 & Sustainability \\
\hline & Demonstrate value & $\begin{array}{l}\text { Continue to deliver pharmacy service and collect data to showcase value } \\
\text { to new leadership once identified (in midst of merger) }\end{array}$ & 7 & Sustainability \\
\hline & Obtain feedback & $\begin{array}{l}\text { Obtain feedback and support from leadership on priority for scalability of } \\
\text { the service through meetings and presentation of pilot data }\end{array}$ & 3 & Scalability \\
\hline Service fit & Clarify needs & $\begin{array}{l}\text { Determine expectations for selecting a service through meetings with } \\
\text { leadership }\end{array}$ & 1 & Implementation \\
\hline \multirow[t]{2}{*}{ Support } & Access coaching & Engage coach to support readiness process & 1 & Implementation \\
\hline & Learn from peers & $\begin{array}{l}\text { Communicate with peers outside of the organization to learn about billing } \\
\text { pathways from providers implementing this service }\end{array}$ & 1 & Implementation \\
\hline
\end{tabular}


Table 5 Progress on strategy execution

\begin{tabular}{lll}
\hline Site & Readiness strategy used & Progress \\
\hline 1 & Build data management system to monitor progress and outcomes (excel spreadsheet, then integration with EPIC) & In progress \\
Identify champion to promote service through discussion with leadership & Complete \\
Leverage champion to develop a billing pathway in order to bill for the service & In progress \\
& Leverage champion to help prepare for implementation & Complete \\
Identify team members responsible for readiness and implementation & Complete \\
& Determine expectations for selecting a service through meetings with leadership (CMM or opioid tapers) \\
& Educate clinic staff about the service through meetings & Complete \\
& Educate staff about their role in service delivery through meetings \\
& Engage coach to support readiness process & In progress \\
Communicate with peers outside of the organization to learn about billing pathways used by providers implementing this & In progress
\end{tabular}

2 Build data management system as a way to monitor progress and outcomes by creating template in EPIC to capture and report In progress on data for the service

Develop a financial plan to sustain the initiative by engaging with leadership and hiring an FTE

In progress

Develop workflow for service after reviewing current best practices in heart failure

Complete

3 Use of pilot data to increase buy-in from leadership for scaling service

In progress

Develop and present a scalability plan showcasing pilot data to obtain additional financial resources through presentations and meetings with leadership

Obtain feedback and support from leadership on priority for scalability of the service through meetings and presentation of pilot In progress data

Train resident on data collection process through meetings and training materials

Not

addressed

4 Engage implementation team through online training and showcasing of positive patient stories to obtain buy-in for the selected In progress service

Develop workflow to integrate new service after completing driver diagram

In progress

Develop training on workflow to get staff confident with service delivery

In progress

Optimize staffing to maximize efficiencies by transitioning roles and responsibilities to mitigate staff turnover

In progress

5 Develop process for tracking patient data

Not

addressed

Develop a referral process for pharmacy service by creating referral form for primary care physicians

In progress

Optimize staffing to maximize efficiencies by modifying roles and responsibilities to allow pharmacist to focus on billable services

6 Use pilot data for gaining approval from partnering health plan for payment model

In progress

Create workflow to meet the capacity needed to reach a larger high-risk patient population

Complete

Develop a payment/billing methodology

In progress

Brainstorm promotional messaging for internal marketing materials with pharmacy managers to increase pharmacist

Complete engagement

Deliver promotional messaging to pharmacists through program champions (i.e., pharmacists on board)

In progress

In progress

7 Determine priority for service by reaching out to new leadership once identified (in midst of merger)

In progress

Continue to deliver pharmacy service and collect data to showcase value to new leadership once identified (in midst of merger)

8 Build data management system as a way to monitor patient progress and outcomes by partnering with IT

In progress

In progress

Create and disseminate marketing materials through multiple avenues of communication (e.g., mailing lists, media outlets) to increase patient and provider engagement in the service

Not

addressed

Develop a centralized repository for patient information by partnering with IT

In progress 
Understanding experience of participating sites with the readiness process (Aim 2)

\section{Facilitators-what promoted use of the readiness process}

Based on the interviews, the elements that facilitated use of the readiness process included having support from a coach, access to a program champion, having an engaged team, and access to the readiness tools. Coaches were reported to be helpful in a number of ways. They assisted with reviewing and understanding the readiness assessment results, facilitated the prioritization process, facilitated planning and execution of the readiness building strategies, provided feedback, reviewed progress, and ensured accountability. Interviewees also commented on the importance of a program champion. The program champion was reported to be leveraged to ensure accountability, influence other stakeholders and help getting readiness tasks accomplished, and connect with leadership about decisions that had an impact on the project (e.g., "our supervisor [champion] helped give us which [health system] person we needed to talk to for the blessing of an FTE"). Having a team who was enthusiastic and motivated, focused on execution, understood priorities, and brainstormed together was also cited as a facilitator (e.g., "the team members were all highly invested...we knew we would not let this fail"). Finally, interviewees highlighted the readiness process and tools as being particularly helpful (e.g., "It made us think and make sure we checked all of the boxes. That we did not miss talking to anyone or considered other alternatives to decisions"). The overall process was useful to help them carefully think through decisions, consider differing viewpoints, and prioritize. Specifically, the RMT data and individualized heatmap reports facilitated identification and framing of readiness issues that needed to be addressed; the priority tool helped organize the readiness issues into meaningful categories; and the action plan served multiple functions, including as a communication tool, a roadmap for readiness building execution and progress tracking, and a strategy to demonstrate the value of pharmacists.

\section{Challenges-what impeded use of the readiness process}

Competing priorities and lack of resources, difficulties with timely decision-making, team issues, and timing of the readiness process emerged as barriers to using the readiness process. Misalignment of priorities at the administrative level included leadership changes, a merger, and functioning within a large bureaucracy. In addition, use of the readiness process was negatively impacted by time and resource constraints. The pharmacists' and clinic stakeholders' responsibilities focused first and foremost on patient care (e.g., "I felt uncomfortable even presenting it [readiness assessment] to anyone else that I worked with in the clinic, because I felt like that would create more of a barrier in terms of adding more work for them"). In addition to competing priorities, simple lack of time (e.g., "we weren't able to devote as much time into the project"), insufficient staffing, and ease of data access (e.g., "...just things like trying to get data, just even baseline data, was very difficult") were cited as resource barriers. The ability to obtain buy-in and make timely decisions due to logistical difficulties (e.g., "getting everybody in a room") and changing priorities (e.g., merger) also influenced completion of readiness activities. Issues within the team, such as turnover and difficulties building a team, emerged as significant hindrances to engaging in the readiness process. Finally, because the readiness process overlapped with implementation of the project at more advanced sites, it was perceived as "being too late" along the project lifecycle.

\section{Lessons learned}

When asked about the advice they would give to a colleague about to engage in the readiness process, interviewees pointed to a number of lessons learned. First, the need to focus the readiness process on a priority service for the healthcare setting was mentioned as being critical to success. Second, the ability to engage others in the readiness process was key to increase buy-in and ensure consideration of multiple perspectives (e.g., "Through that readiness assessment tool I think we learned that we needed input from IT; we needed input from our quality assurance person; so just having all the disciplines that you really need to build the program [...] would have been beneficial"). In addition, communicating and sharing progress across the clinic was reported to legitimize this readiness work. Third, having access to a structured process was found to be valuable to identify priorities, provide a roadmap for action, monitor progress, and facilitate the development of a step-by-step readiness building approach. However, because the readiness process can be time and resource intensive, it was recommended that it be rightsized to the needs of the initiative (e.g., "I kind of like the whole concept, and I've been adapting some of the concepts for smaller projects, just not doing the whole assessment") and to organizational maturity level (e.g., "I feel like organizations that were more building from the ground up... could benefit"). Interviewees also pointed out the importance of timing. The readiness process is most valuable early in the project lifecycle, prior to implementation.

\section{Discussion}

Readiness is an essential precursor of successful implementation; however, its conceptualization and application have proved elusive. $\mathrm{R}=M C^{2}$ operationalizes readiness for use in practice. Yet, its use and value have 
not been explored. The purpose of this study was to (1) describe application of $\mathrm{R}=M \mathrm{C}^{2}$ to assess and build readiness in a cohort of nine healthcare sites responsible for implementing medication management services and (2) gain insights into the sites' experience with this process. To our knowledge, this is the first published study to systematically explore operationalization of the $\mathrm{R}=\mathrm{MC}^{2}$ system, with the purpose being to better understand its value in real-world settings.

\section{Insights into use of the readiness process}

Use of the readiness process was synthesized by examining who was involved, what readiness challenges and strategies were identified, how much progress was made toward strategy execution, and to what purpose. Involved in the study were primary care and specialty clinics within health systems, outpatient pharmacies within health systems, and community pharmacies. Teams consisted of 4-11 members, including a lead pharmacist, although completion of the readiness process ended up being the responsibility of 1-3 individuals per team. This type of team structure reflects best practice guidance on building effective teams, with select core members accomplishing the work and other stakeholders participating in an advisory or linkage capacity [36]. Although each team had unique sets of readiness challenges, the readiness building strategies selected for execution clustered into five broad categories (i.e., building the operational infrastructure for service integration, identification and leveraging of teams and champions, stakeholder engagement and buy-in, alignment of priorities and service fit, and the need to access external implementation supports). Previous literature identified similar preparation domains for successful implementation [37-40]. Of the 34 strategies identified across sites, $68 \%$ were still in progress after 4 months. Readiness building might require additional time, with previous guidance highlighting the need to continue the process throughout the project lifecycle [20,31, 41]. Determining the essential aspects of readiness for each implementation stage might be helpful to focus readiness activities. Finally, engaging in the readiness work was associated with a number of benefits (e.g., increased awareness of readiness challenges, an opportunity to ensure alignment of priorities and fit of the intervention). These benefits align with previous research on implementation capacity. Anticipating challenges, assessing fit, obtaining buy-in, and adopting a systematic approach to organizing and tracking progress have been identified as critical precursors of successful implementation [42, 43]. The readiness process also resulted in varied operational outputs (e.g., data management systems, service billing methodologies). These outputs are consistent with the infrastructure needed to implement medication optimization services [44]. Assessing and building readiness seemed to therefore facilitate the identification and development of critical processes and infrastructure for service delivery.

\section{Insights into the sites' experience with the readiness process}

First, identifying and building internal supports, such as an accountable team and a champion, were cited as both readiness challenges and facilitators. Although both the team and the champion were reported to help with accountability, they also had different roles. The team served to support the champion's efforts and assist with discrete tasks, while the champion promoted the change and facilitated execution of readiness activities within the care setting. Previous research has identified internal teams and champions as critical precursors of successful planning, implementation, and sustainability of interventions [38, 39, 45-49].

Second, the need to engage and communicate with others within the organization (i.e., healthcare providers, administrative staff, leadership) to build buy-in and promote action was mentioned as a readiness challenge and lesson learned. Advocacy, social mobilization, the ability to incorporate multiple perspectives, and the capacity to navigate the political environment of an organization have all been recognized as necessary relational skills to drive change [38, 47, 50]. Getting others within care delivery settings to embrace the readiness process and understand its benefits (i.e., preparing for successful implementation of a service) is no exception.

Third, attending to priorities was emphasized as both a lesson learned and a potential barrier. Engaging in readiness was reported to facilitate alignment of service priorities for the clinic and health system. However, more pressing demands often limited the amount of time and resources that could be allocated to this process. This highlights the needs and resourcing tensions that exist in busy healthcare practices with competing responsibilities.

Finally, participating sites emphasized the value of having access to a methodical approach and external supports (i.e., coaching, tools) to be able to effectively use the readiness process. These findings are aligned with previous literature emphasizing the need for active capacity building strategies along the broad implementation continuum (from planning to sustainability) [51-53]. Participants also noted the need to rightsize the readiness process based on the complexity of the service and time its use early in the project lifecycle. The ability to adapt processes and systems (regardless of content), with availability of "light" versions for busy users, has been previously recognized [54-56]. 


\section{Limitations}

Although this study yields interesting findings, it is not without limitations. First, this study aimed to explore application of the $\mathrm{R}=\mathrm{MC}^{2}$ system. As a naturalistic observational study, its utility is not in assessing the effectiveness of the readiness process but rather in gaining early insights into use of a readiness system. Second, both the sample size and the recruitment approach into the CMMA initiative limit generalizability of the findings. This research might be particularly relevant for clinics, health systems, and pharmacies that already demonstrate a certain level of motivation and ability to implement a new service. Finally, the fact that the readiness process overlapped with implementation of the service needs to be considered in the interpretation of the data. It is important to note that engaging simultaneously (rather than sequentially) in planning and implementation is more likely to reflect what actually occurs in busy practices.

\section{Conclusion}

In conclusion, this study provides early insights into the value of a readiness process, $\mathrm{R}=M \mathrm{C}^{2}$, for healthcare settings implementing a pharmacy care intervention. Readiness should be considered as an essential aspect of any implementation planning process, alongside other preparatory activities such as conducting needs and resources assessments, goal setting, patient engagement, review of available best practice interventions, and development of implementation plans. Future research could build on these findings in a number of ways, including further exploring the optimal readiness process for different needs and contexts; evaluating the impact of readiness building strategies on implementation effectiveness, and ultimately patient outcomes; and further refining the conceptualization of readiness by identifying essential components and defining readiness thresholds for each implementation stage. If readiness is to be integrated into routine practice as part of any implementation effort, it is critical to gain a better understanding of its application, value, and effectiveness.

\footnotetext{
Abbreviations

AIMM: Alliance for Integrated medication Management;

CMM: Comprehensive medication management; CMMA: Concordia

Medication Management Accelerator; CMO: Center for Medication

Optimization; CMR: Comprehensive medication review; CUW: Concordia

University Wisconsin; Med Sync: Medication synchronization;

MTM: Medication therapy management; RMT: Readiness monitoring tool
}

\section{Acknowledgements}

We would like to acknowledge Todd Sorensen, PharmD, Executive Director of AIMM, and Andrew Traynor, PharmD, BCBS, Associate Professor and Chair of Pharmacy Practice at Concordia University Wisconsin School of Pharmacy, for supporting use of the readiness process with the AIMM CMMA cohort, and The Wandersman Center for providing technical support on use of the $R$ $=M C^{2}$ framework

\section{Authors' contributions}

ML designed the study, developed study materials, managed implementation of the readiness process and execution of the research study, synthesized the information presented in this study, and wrote the manuscript. MY conducted the interviews and performed the preliminary content analysis, prepared the initial tables and figures, and contributed to the document review. CR contributed to the document review and the content analysis, and prepared the readiness reports. LS and PS served as coaches to the participating teams, completed the coaching logs, and assisted the research team with data collection as needed. The authors read and approved the final manuscript.

\section{Funding}

The CMMA initiative was sponsored by Concordia University Wisconsin's School of Pharmacy (CUW-SOP) in partnership with CUW's Batterman School of Business and with a personal gift from Erv Dohmen; the research conducted as part of the initiative was unfunded.

\section{Availability of data and materials}

The datasets used and/or analyzed during the current study are available from the corresponding author on reasonable request

Ethics approval and consent to participate UNC IRB

\section{Consent for publication}

Not applicable

\section{Competing interests}

The authors declare that they have no competing interests

\section{Author details}

${ }^{1}$ Center for Medication Optimization (CMO), Division of Practice Advancement and Clinical Education, Eshelman School of Pharmacy, University of North Carolina at Chapel Hill, Chapel Hill, NC, USA. ${ }^{2}$ Alliance for Integrated Medication Management, Minneapolis, MN, USA. ${ }^{3}$ Department of Pharmaceutical Care and Health Systems, College of Pharmacy, University of Minnesota, Minneapolis, MN, USA. ${ }^{4}$ Financial Transformations Inc., Fairfax, VA, USA.

Received: 17 October 2019 Accepted: 22 April 2020

Published online: 10 June 2020

\section{References}

1. Drzensky F, Egold N, van Dick R. Ready for a change? A longitudinal study of antecedents, consequences and contingencies of readiness for change. $J$ Chang Manag Taylor \& Francis. 2012;12:95-111.

2. Greenhalgh T, Robert G, Macfarlane F, Bate P, Kyriakidou O. Diffusion of innovations in service organizations: systematic review and recommendations. Milbank Q. 2004;82:581-629.

3. Hall GE, Hord SM, Aguilera R, Zepeda O, von Frank V. Implementation: learning builds the bridge between research and practice. J Staff Dev. 2011; 32:52-7.

4. Holt DT, Vardaman JM. Toward a comprehensive understanding of readiness for change: the case for an expanded conceptualization. J Chang Manag Taylor \& Francis. 2013;13:9-18.

5. Dwayne Simpson D. Organizational readiness for stage-based dynamics of innovation implementation. Res Soc Work Pract. Sage Publications Sage CA: Los Angeles, CA; 2009;19:541-551.

6. Weiner BJ. A theory of organizational readiness for change. Implement Sci. 2009;4:67.

7. Rafferty $A E$, Jimmieson NL, Armenakis AA. Change readiness: a multilevel review. J Manag. Sage Publications Sage CA: Los Angeles, CA; 2013;39:110135.

8. Weiner BJ, Amick H, Lee S-YD. Conceptualization and measurement of organizational readiness for change: a review of the literature in health services research and other fields. Med Care Res Rev. Sage Publications Sage CA: Los Angeles, CA; 2008;65:379-436.

9. Weiner BJ, Lewis MA, Linnan LA. Using organization theory to understand the determinants of effective implementation of worksite health promotion programs. Health Educ Res Oxford University Press. 2009;24:292-305. 
10. Kotter JP. Leading Change. Boston: Harvard Business School Press; 1996.

11. Livet M, Blanchard C, Sorensen TD, Roth MCM. An implementation system for medication optimization: operationalizing comprehensive medication management delivery in primary care. J Am Coll Clin Pharm. 2018;1:14-20.

12. Damschroder LJ, Aron DC, Keith RE, Kirsh SR, Alexander JA, Lowery JC. Fostering implementation of health services research findings into practice: a consolidated framework for advancing implementation science. Implement Sci. 2009;4:50.

13. Aarons GA, Hurlburt M, Horwitz SM. Advancing a conceptual model of evidence-based practice implementation in public service sectors. Adm Policy Ment Health [Internet]. 2011;38:4-23. Available from: http://www.ncbi. nlm.nih.gov/pubmed/21197565\%5Cnhttp://www.pubmedcentral.nih.gov/ articlerender.fcgi?artid=PMC3025110.

14. Powell BJ, MCMillen JC, Proctor EK, Carpenter CR, Griffey RT, Bunger AC, et al. A compilation of strategies for implementing clinical innovations in health and mental health. Med care Res Rev MCRR [Internet]. 2012;69:12357. Available from: http://www.pubmedcentral.nih.gov/articlerender. fcgi?artid=3524416\&tool=pmcentrez\&rendertype=abstract.

15. Shea CM, Jacobs SR, Esserman DA, Bruce K, Weiner BJ. Organizational readiness for implementing change: a psychometric assessment of a new measure. Implement Sci BioMed Central. 2014;9:7.

16. Flaspohler PD, Meehan C, Maras MA, Keller KE. Ready, willing, and able: developing a support system to promote implementation of schoolbased prevention programs. Am J Community Psychol Springer. 2012; 50:428-44.

17. Collins C, Phields ME, Duncan T. An agency capacity model to facilitate implementation of evidence-based behavioral interventions by communitybased organizations. Public Heal Manag Pract. 2007;suppl:S16-S23.

18. Batras D, Duff C, Smith BJ. Organizational change theory: implications for health promotion practice. Health Promot Int Oxford University Press. 2016; 31:231-41.

19. Adhikari H. Organizational change models: A comparison. Available SSRN 1016981. 2007;

20. Scaccia JP, Cook BS, Lamont A, Wandersman A, Castellow J, Katz J, et al. A practical implementation science heuristic for organizational readiness: $R=$ MC2. J Community Psychol. 2015;43:484-501.

21. Klein KJ, Knight AP. Innovation implementation: overcoming the challenge. Curr Dir Psychol Sci. 2005;14:243-6.

22. Kingston B, Mattson SA, Dymnicki A, Spier E, Fitzgerald M, Shipman K, et al. Building schools' readiness to implement a comprehensive approach to school safety. Clin Child Fam Psychol Rev. 2018;21:433-49.

23. Domlyn AM, Wandersman A. Community coalition readiness for implementing something new: using a Delphi methodology. J Community Psychol Wiley Online Library. 2019;47:882-97.

24. Curran GM, Shoemaker SJ. Advancing pharmacy practice through implementation science. Res Soc Adm Pharm Elsevier. 2017;13:889-91.

25. Livet M, Haines ST, Curran GM, Seaton T, Ward C, Sorensen T, et al. Implementation science to advance care delivery: a primer for pharmacists and other health professionals. Pharmacotherapy. 2018;38:490-502.

26. IQVIA Institute. Medicines use and spending in the U.S.: a review of 2016 and outlook to 2021. 2017. https://www.iqvia.com/institute/reports/ medicines-use-and-spending\%0A-in-the-us-a. Accessed 25 July 2018.

27. Watanabe JH, Mclnnis T, Hirsch JD. Cost of prescription drug-related morbidity and mortality. Ann Pharmacother. 2018:1-9.

28. Greer N, Bolduc J, Geurkink E, Rector T, Olson K, Koeller E, et al. Pharmacistled chronic disease management: a systematic review of effectiveness and harms compared with usual care. Ann Intern Med. 2016;165:30-40.

29. Viswanathan M, Kahwati LC, Golin CE, Blalock SJ, Coker-Schwimmer E, Posey $R$, et al. Medication therapy management interventions in outpatient settings: a systematic review and meta-analysis. JAMA Intern Med. 2015;175: 76-87.

30. AIMM: Alliance for Integrated Medicated Management. http://aimmweb. org/. Accessed 16 Sept 2019

31. Wandersman A, Scaccia JP. Organizational readiness: measurement and as a predictor of progress: final report. Prepared for the Robert Wood Johnson Foundation. Award \# 35497. 2017.

32. Gill P, Stewart K, Treasure E, Chadwick B. Methods of data collection in qualitative research: interviews and focus groups. Br Dent J Nature Publishing Group. 2008;204:291.

33. Bowen GA. Document analysis as a qualitative research method. Qual Res J Emerald Group Publishing Limited. 2009;9:27-40.
34. Hill CE, Knox S, Thompson BJ, Williams EN, Hess SA, Ladany N. Consensual qualitative research: an update. J Couns Psychol American Psychological Association. 2005;52:196.

35. Hsieh HF, Shannon SE. Three approaches to qualitative content analysis. Qual Health Res. 2005;15:1277-88.

36. National Implementation Research Network. Topic 4: establishing implementation teams. https://nirn.fpg.unc.edu/module-3/topic-4. Accessed 18 Sept 2019

37. Done A, Voss C, Rytter NG. Best practice interventions: short-term impact and long-term outcomes. J Oper Manag. 2011;29:500-13.

38. Durlak JA, DuPre EP. Implementation matters: a review of research on the influence of implementation on program outcomes and the factors affecting implementation. Am J Community Psychol. 2008;41: 327-50.

39. Stone $A B$, Yuan $C T$, Rosen MA, Grant MC, Benishek LE, Hanahan E, et al. Barriers to and facilitators of implementing enhanced recovery pathways using an implementation framework: a systematic review. JAMA Surg American Medical Association. 2018;153:270-9.

40. Meyers DC, Durlak JA, Wandersman A. The quality implementation framework: a synthesis of critical steps in the implementation process. Am J Community Psychol. 2012:50:462-80.

41. Scott VC, Kenworthy T, Godly-Reynolds E, Bastien G, Scaccia J, McMickens C, et al. The Readiness for Integrated Care Questionnaire (RICQ): an instrument to assess readiness to integrate behavioral health and primary care. Am J Orthopsychiatry Educational Publishing Foundation. 2017:87:520.

42. Livet $M$, Courser $M$, Wandersman $A$. The prevention delivery system: organizational context and use of comprehensive programming frameworks. Am J Community Psychol. 2008;41:361-78.

43. Flaspohler P, Duffy J, Wandersman A, Stillman L, Maras MA. Unpacking prevention capacity: an intersection of research-to-practice models and community-centered models. Am J Community Psychol. 2008;41:182-96.

44. Pestka DL. Assessing the components needed to support and operate Comprehensive Medication Management in primary care clinics; 2018

45. Higgins MC, Weiner J, Young L. Implementation teams: a new lever for organizational change. J Organ Behav Wiley Online Library. 2012;33:366-88.

46. Metz A, Bartley L. Active implementation frameworks for program success. Zero Three. 2012;32:11-8.

47. Kadu MK, Stolee P. Facilitators and barriers of implementing the chronic care model in primary care: a systematic review. BMC Fam Pract BioMed Central. 2015;16:12.

48. Urquhart R, Porter GA, Sargeant J, Jackson L, Grunfeld E. Multi-level factors influence the implementation and use of complex innovations in cancer care: a multiple case study of synoptic reporting. Implement Sci BioMed Central. 2014;9:121.

49. Miech EJ, Rattray NA, Flanagan ME, Damschroder L, Schmid AA, Damush TM. Inside help: an integrative review of champions in healthcare-related implementation. SAGE open Med. SAGE Publications Sage UK: London, England; 2018;6:2050312118773261

50. Hoag BG, Ritschard HV, Cooper CL. Obstacles to effective organizational change: the underlying reasons. Leadersh Organ Dev J MCB UP Ltd. 2002; 23:6-15.

51. Leeman J, Calancie L, Hartman MA, Escoffery CT, Herrmann AK, Tague LE, et al. What strategies are used to build practitioners' capacity to implement community-based interventions and are they effective?: a systematic review. Implement Sci. 2015;10:80.

52. Powell BJ, Waltz TJ, Chinman MJ, Damschroder LJ, Smith JL, Matthieu MM, et al. A refined compilation of implementation strategies: results from the Expert Recommendations for Implementing Change (ERIC) project. Implement Sci [Internet]. 2015;10:21. Available from: http:// implementationscience.biomedcentral.com/articles/10.1186/s13012-015-02 09-1.

53. Brouwers MC, De Vito C, Bahirathan L, Carol A, Carroll JC, Cotterchio M, et al. What implementation interventions increase cancer screening rates? A systematic review. Implement Sci BioMed Central. 2011;6:111.

54. Livet M, Fixsen A. Adapting a technology-based implementation support tool for community mental health: challenges and lessons learned. Health Promot Pract. 2018. 
55. Backer TE. Finding the balance: program fidelity and adaptation in substance abuse prevention: a state-of-the-art review. Rockville, MD: Cent. Subst. Abus. Prev; 2002.

56. Rogers EM. Diffusion of innovations. New York, NY: Free Press; 1995.

\section{Publisher's Note}

Springer Nature remains neutral with regard to jurisdictional claims in published maps and institutional affiliations.

- fast, convenient online submission

- thorough peer review by experienced researchers in your field

- rapid publication on acceptance

- support for research data, including large and complex data types

- gold Open Access which fosters wider collaboration and increased citations

- maximum visibility for your research: over $100 \mathrm{M}$ website views per year

At BMC, research is always in progress. 